\title{
Köpeklerde Xylazine Uygulamasına Bağlı Gelișen Bulantı ve Kusmanın Önlenmesinde Antihistaminik Kullanımı
}

\author{
M. Kazım BÖRKÜ* Yunusemre ÖZKANLAR $^{* *} \quad$ Başak HANEDAN $^{*} \quad$ Kerem URAL*
}

Geliş Tarihi: 23.05.2005

Kabul Tarihi: 04.04.2006

\begin{abstract}
Özet: Bir $\alpha_{2}$ adrenoreseptör agonisti olan xylazine uygulamasina bağlı olarak köpeklerde bradikardi, hipotansiyon, hipopnea, bulantı ve kusma gibi yan etkiler görülebilmektedir. Bu çalışma xylazine hydrochloride'e bağlı oluşan bulantı ve kusmanın önlenmesinde bir $\mathrm{H}_{1}$ reseptör antagonisti olan mepyramine maleate'ın etkinliğinin araştırılması amacıyla yapıldı. Çalışmada 30 köpek kullanıldı ve köpekler 10'arlı 3 gruba ayrıldı. Çalışmada antihistaminik uygulamasının yapıldığı an 0 . dakika kabul edilerek, birinci guruptakilere $1 \mathrm{mg} / \mathrm{kg}$, ikinci gruptakilere $2 \mathrm{mg} / \mathrm{kg}$ dozda intramuskuler (i.m.) mepyramine ve üçüncü gruptakilere ise eşit miktarda i.m. serum fizyolojik enjeksiyonu yapıldı. Bütün köpeklere bu enjeksiyonlardan 20 dakika sonra 2,2 mg/kg dozda i.m. xylazine enjekte edildi. Xylazine enjeksiyonundan sonra birinci ve ikinci gruptakilerden birer köpek kusarken üçüncü gruptakilerden sekiz köpek kustu. Üçüncü gruptakilerden dokuzunda bulantı gözlenirken, birinci grupta 2 ve ikinci grupta 3 köpekte bulantı saptandı. Birinci ve ikinci gruplarda mepyramine uygulamasından sonraki 40., 60. ve 80. dakikalarda (xylazine uygulamasından sonraki 20., 40. ve 60. dakikalar) pulzasyon ve respirasyon önemli $(\mathrm{P}<0,001)$ oranda düşerken, beden isılarındaki düşüşün istatistiksel önemi yoktu. Sonuç olarak, köpeklerde mepyramine'in xylazine'e bağlı bulantı ve kusmanın önlenmesinde etkili olduğu, diğer parametrelerde istatistik önemi bulunan bir değişikliğin olmadığı belirlendi.
\end{abstract}

Anahtar Kelimeler: Köpek, xylazine, mepyramine maleate, kusma, antihistaminik.

\section{Antihistaminic Administration to Prevent Nausea and Vomiting Induced By Xylazine in Dogs}

\begin{abstract}
Summary: Xylazine, $\alpha_{2}$-adrenoreceptor agonist, may adversely cause bradycardia, hypotension, hypopnea, nausea and vomiting in dogs. This study was performed to investigate the effect of mepyramine maleate, an antihistaminic, on the prevention of vomiting and nausea after administration of xylazine hydrochloride. Thirty dogs were used in this study and they were divided into three groups of ten dogs each. After having assigned the point of antihistaminic administration as 0 minute in the study, mepyramine was injected intramuscularly (i.m.) $1 \mathrm{mg} / \mathrm{kg}$ for group I and $2 \mathrm{mg} / \mathrm{kg}$ for group II and equivalent volume of physiologic serum was injected i.m. for group III. Xylazine, 2.2 $\mathrm{mg} / \mathrm{kg}$ i.m., was injected to all dogs 20 minutes after mepyramine administration. While one dog vomited from group I and group II, eight dogs vomited in group III after xylazine administration. Nausea was detected in two dogs of group I, in three of group II and in nine of group III. Pulsation and respiration decreased significantly $(\mathrm{P}<0.001)$, and body temperatures declined insignificantly at $40^{\text {th }}, 60^{\text {th }}$ and $80^{\text {th }}$ minutes relative to mepyramine administration $\left(20^{\text {th }}, 40^{\text {th }}\right.$ and $60^{\text {th }}$ minutes relative to xylazine administration) in group I and group II. In conclusion, mepyramine is effective to prevent nausea and vomiting induced by xylazine in dogs and any changes were not found over other parameters statistically significant.
\end{abstract}

Key Words: Dog, xylazine, mepyramine maleate, vomiting, antihistaminic.

\footnotetext{
* Ankara Üniversitesi, Veteriner Fakültesi, İç Hastalıklar Anabilim Dalı, Ankara/Türkiye.

** Atatürk Üniversitesi, Veteriner Fakültesi, İç Hastalıklar Anabilim Dalı, Erzurum/Türkiye.
} 


\section{Giriş}

Xylazine merkezi sinir sistemindeki $\alpha_{2}$ adrenerjik reseptörleri uyarıp, norepinefrin salınımını bloke ederek sedasyon, analjezi ve kas gevşemesi sağlar ${ }^{12,14,16}$. Sempatik etkiyi azaltıp parasempatik etkiyi artırması kalp frekansında \% 50-60 azalma (bradikardi), kardiyak output, kan basinc1 ve solunum frekansında düşmeye (hipopnea) neden olur ${ }^{4,16}$. Ayrica xylazine'in kalp bloğu, bulant1, kusma, , gastrointestinal sistemde atoni ve gaz birikmesi gibi yan etkileri bulunmaktadır. Xylazine vagal tonda artışa nedene olarak bradikardi ve aritmi meydana getirmektedir ${ }^{16}$. Xylazine'in $2 \mathrm{mg} / \mathrm{kg}$ dozda kedilerin ${ }^{8}$ tamamında ve köpeklerin ${ }^{9} \% 81$ 'inde kusmaya neden olduğu bildirilmiștir.

Bulant1 ve kusma fonksiyonel olarak iki merkez tarafindan kontrol edilmektedir. Bunlar medulla oblongatadaki medullar kusma merkezi ve dördüncü ventrikülün tabanında area postremadaki kemoreseptör trigger zon'dur (KTZ). Medullar kusma merkezi, uyarıları gastrointestinal kanal ve vücudun diğer kısımlarından aldığı gibi, beyin kökü ve korteksinden özelliklede, labirent aparat ve KTZ'dan almaktadır. KTZ tek başına kusmayı başlatamaz fakat bir kusma kemoreseptörü olarak görev yapar. KTZ opioidler (apomorfin v.s.), dopamin, xylazine, dijitaller, bakteri toksinleri, üremi ve hipoksi sırasında oluşan metabolik bozukluklar tarafindan aktive edilebilmektedir ${ }^{3,6,17}$. Kedilerde xylazine'nin KTZ'u aktive ederek kusmaya neden olduğu gösterilmiştir ${ }^{3}$. Bulantı ve kusmanın oluşmasında histaminerjik, serotonerjik $\left(5-\mathrm{HT}_{3}\right)$, dopaminerjik, muskarinik ve diğer reseptörler ile postoperatif kusmanın önlenmesinde bu reseptörlere yönelik antagonistler araştırılmakta$\mathrm{d}_{1} \mathrm{r}^{2,5,11,13,19,20}$.

Histamin vücutta değişik yerlerden salg1lanmaktadır. Merkezi sinir sistemindeki (MSS) sinirlerden histamin salgılanır ve sinir uçlarında depo edilir, buna beyin histamini adi verilir. Ayrıca, mide pariyetal hücrelerine yakın bulunan enterokromafin hücrelerden de salgılanır. Anestezik, hipnotik ve kas gevşeticileri midedeki histamin salınımını artıırlar. Enterokromafin hücrelerden salgılanan histamin pariyetal hücrelerdeki $\mathrm{H}_{2}$ reseptörlerine bağlanarak asit ve pepsin salgisını artırır. Buda gastrik sıv1 miktarı ve asiditede artışa neden olur ${ }^{15,17}$. Histaminin asıl sentezlendiği ve depolandığg yer gerçekte bir bağ doku hücresi olan mast hücresidir. Vücutta hisamin salınımında antijen, toksin, bazı enzim ve alkaloidlerin (morfin gibi) etkinliği belirlenmiştir. Morfin, amin ve amid yapısındaki bazı ilaçlar mast hücreleri içine girerek granüller içinde toplanır ve histaminin salınmasını sağlarlar. Histamin hücre zarları üzerindeki özel reseptörlere $\left(\mathrm{H}_{1}, \mathrm{H}_{2}\right.$ ve $\left.\mathrm{H}_{3}\right)$ bağlanarak etki gösterir. $\mathrm{H}_{1}$ reseptörleri düz kas, endotel ve beyinde, $\mathrm{H}_{2}$ reseptörleri mide mukozası, kalp kası, mast hücreleri ve beyinde, $\mathrm{H}_{3}$ reseptörleri perisinaptik olarak beyin, myenterik pleksus ve diğer nöronlarda bulunur. Midede asit salgilayan pariyetal hücrelerde $\mathrm{H}_{2}$ reseptörleri bulunurken bağırsak düz kaslarında $\mathrm{H}_{1}$ reseptörleri bulunur. Beyinde daha çok $\mathrm{H}_{1}$ ve $\mathrm{H}_{3}$ reseptörleri bulunur ${ }^{17}$. Area postrema bölgesine histamin enjekte edildiğinde kusmaya neden olduğu bilinmektedir ${ }^{1}$.

Antihistaminikler $\mathrm{H}_{1}, \mathrm{H}_{2}$ ve $\mathrm{H}_{3}$ reseptör antagonistleri olarak üçe ayrılmaktadır. Bunlardan $\mathrm{H}_{1} \quad$ reseptör antagonistlerine klasik antihistaminikler denilir. Klasik antihistaminiklerin MSS'inde yatıştırıcı ve kusma kesici etkileri vardır. Unseld ve ark. (1996) perioperatif kusma ve bulantının önlenmesinde $\mathrm{H}_{1}$ ve $\mathrm{H}_{2}$ reseptör antagonistlerinin etkilerini göstererek kusmanın patogenezinde histaminin rol oynayabileceğini vurgulamışlardır. Son yıllarda yapılan çalışmalar histamin $^{11}$ ve serotonin ${ }^{19}$ mediatörleri seviyeleri ile kusma arasında bir ilişki olduğu ortaya konulmuştur.

Bir preanestezik ve sedatif olan xylazine uygulamasından sonra köpeklerde yaygın olarak bulantı ve kusma gözlemlenmektedir. Yapılan çalışmalar ${ }^{11,15}$ perioperatif olarak anesteziklerin oluşturduğu düşünülen bulantı ve kusmanın önlenmesinde antihistaminik uygulamalarının etkili olabileceğini düşündürmektedir. $\mathrm{Bu}$ çalışma xylazine bağlı kusma ve bulantının önlenmesinde bir antihistminik $\left(\mathrm{H}_{1}\right.$ reseptör antagonisti) olan mepiramine'in etkinliğinin araştırması amacıyla yapild.

\section{Materyal ve Metot}

Bu çalışmada erişkin, farklı cinsiyette, melez, ortalama $14,7 \pm 3,2 \mathrm{~kg}$ canlı ağırlıkta, klinik yönden sağlıklı 30 adet köpek kullanıldı. Köpeklerin paraziter mücadeleleri ve aşıları yapıldı. Köpekler 10'arlı 3 gruba ayrıldı. Köpekler çalışmaya başlamadan 12 saat önce beslendiler ve ad libitum su verildi. Çalışmada, antihistaminik uygulamasının yapıldığı an 0. dakika olarak kabul edildi. Birinci gruptakilere 0. dakikada $1 \mathrm{mg} / \mathrm{kg}$ 
canlı ağırlık dozunda bir antihistaminik $\left(\mathrm{H}_{1}\right.$ reseptör antagonisti) olan mepyramine maleate (Histavet, 20mg mepyramine maleate/ml, Vetaş) 20. dakikada $2,2 \mathrm{mg} / \mathrm{kg}$ canlı ağırlık dozunda xylazine hydrochloride (2 (2,6 - dimethylphenylamino) $-4 \mathrm{H}-5,6$ - dihydro - 1,3 thiazine hydrochloride) (Alfazyne, \%2, Ege Vet $\left.{ }^{\circledR}\right)$, II. gruptakilere 0 . dakikada $2 \mathrm{mg} / \mathrm{kg}$ canlı ağırlık dozunda mepyramine 20. dakikada 2,2 $\mathrm{mg} / \mathrm{kg}$ canlı ağırlı dozunda xylazine hydrochloride, III. gruptakilere 0. dakikada eşit miktarda i.m. serum fizyolojik, 20. dakikada 2,2 $\mathrm{mg} / \mathrm{kg}$ canlı ağırlık dozunda xylazine gluteal kastan i.m. enjekte edildi. Köpeklerde 0., 20., 40., 60 . ve 80 . dakikalarda xylazine enjeksiyonundan sonra bulant1, öğürme ve kusma semptomu gösterip göstermedikleri ve pulzasyon, respirasyon, rektal beden isısı değerleri kaydedildi. Solunumda hizlanma, yalanma ve salya akıntısı gibi bulant1 semptomları ve kusma belirlenen hayvan say1ları ve mepiramine'in etkinliği yüzde olarak verildi. Ögüurme semptomu gösteren hayvanlar kusma grubu içerisinde değerlendirildi.

Tüm gruplarda mepyramine ve xylazine'in klinik parametreler üzerine etkilerinin karşılaştırılabilmesi için gruplar arası 0., 20., 40., 60. ve 80. dakikalar arasındaki istatistik analizler "ANOVA çift yönlü tekrarlı ölçüm yöntemi” ile yapıldı. Fistatistik yöntemine göre önemlilik dereceleri belirlendi ve Tukey post hoc testinde $\mathrm{P}<0,05$ önemli olarak değerlendirildi. Elde edilen verilerin ortalamaları kullanıldı ve standart sapmaları hesapland1.

\section{Bulgular}

Bütün köpekler çalışma öncesi sağlıklı ve klinik olarak normal görünümde ve sakindiler. Antihistaminik uygulamasından 20 dakika sonra bütün köpekler klinik olarak normal görünümdeydi. Xylazine uygulamasından sonra birinci $(n=10)$ ve ikinci $(n=10)$ gruptan birer köpek kusarken, üçüncü $(n=10)$ gruptan 8 köpek kustu (Tablo I) (Şekil 1). Birinci grupta 2, ikinci grupta 3 ve üçüncü grupta 9 köpek solunumda hızlanma, yalanma ve salya akıntıs1 ile karakterize bulantı semptomu gösterdi (Tablo I) (Şekil 4). Mepyramine uygulamasının xylazine bağlı kusmanın önlenmesinde her iki grupta \% 87,5 oranında, bulantının önlenmesinde birinci grupta \% 66,6 ve ikinci grupta $\% 77,7$ oranında etkili olarak hesaplandi. 0. dakikada birinci grupta pulzasyon sayıları ortalama $112 \pm 6,5$, ikinci grupta $128,3 \pm 5,8$ ve üçüncü grupta $124,1 \pm 12$; respirasyon sayıları ortalama birinci grupta $30,3 \pm$ 1,7 , ikinci grupta $29,3 \pm 2,4$ ve üçüncü grupta $27,3 \pm 1$; ortalama rektal beden 1silar1 $38,8 \pm 0,13$, ikinci grupta $38,73 \pm 0,12$ ve üçüncü grupta 38,86 $\pm 0,11$ derece idi. Antihistaminik uygulamasindan 20 dakika sonra istatistiksel olarak önemli bir değişiklik saptanmazken, birinci ve ikinci gruplarda pulzasyon sayısı hafif düştü, respirasyon sayıs1 ve beden 1sısı hafif yükseldi (Şekil 2,3,4). Çalışmanın 40. dakikasında (xylazine uygulamasindan 20 dakika sonra) bütün gruplarda pulzasyon ve respirasyon sayılarında önemli düşüş saptandı $(\mathrm{p}<0,001)$ (Şekil 2 ve 3$)$. Pulzasyon ve respirasyon sayılarındaki bu düşüler 60 . ve 80 . dakikalarda aynıydı. Çalışmanın 80. dakikasında ortalama rektal beden 1silar1 birinci, ikinci ve üçüncü gruplarda sirasıly $38,55 \pm 0,07$ $(\mathrm{p}=0,095), 38,38 \pm 0,14(\mathrm{p}=0,081), 38,36 \pm 0,18$ $(\mathrm{p}=0,067)$ olarak belirlendi. Pulzasyon, respirasyon ve rektal beden isılarında gruplar arasinda istatistiksel fark saptanmadi. Bütün gruplarda xylazine uygulamasindan sonra beden isisinda hem gruplar arası hem de sıfır değerlerine göre istatistik önemi olmayan hafif düşme saptanırken, antihistaminik uygulanan birinci ve ikinci gruplarda üçüncü gruba göre belirlenen düşüş daha az bulundu (Şekil 4).

\section{Tablo I. Deneme ve kontrol grubu köpeklerde bulantı ve kusma sayıları}

Table I. Numbers of nausea and vomiting in control and working groups.

\begin{tabular}{|l|c|c|c|}
\hline & Grup I $(\mathrm{n}=10)$ & Grup II $(\mathrm{n}=10)$ & Grup III $(\mathrm{n}=10)$ \\
\hline Kusma & 1 & 1 & 8 \\
\hline Bulantı & 3 & 2 & 9 \\
\hline
\end{tabular}

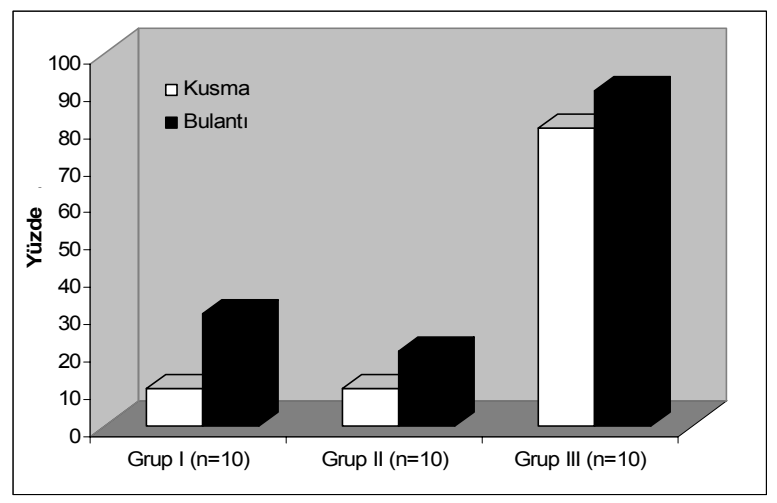

Şekil 1.

Deneme ve kontrol grubu köpeklerde bulantı ve kusma oranları

Figure 1.

Ratios of nausea and vomiting in control and working groups. 


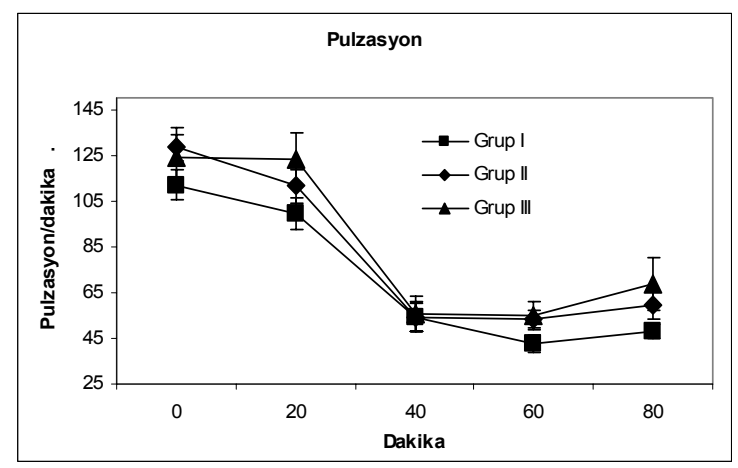

Sekil 2.

Deneme ve kontrol grubu köpeklerde ortalama pulzasyon ve standart sapmalart. ***: $p<0,001$. Figure 2.

Mean of pulsation and its standard deviation in control and working groups. ***: $p<0,001$.

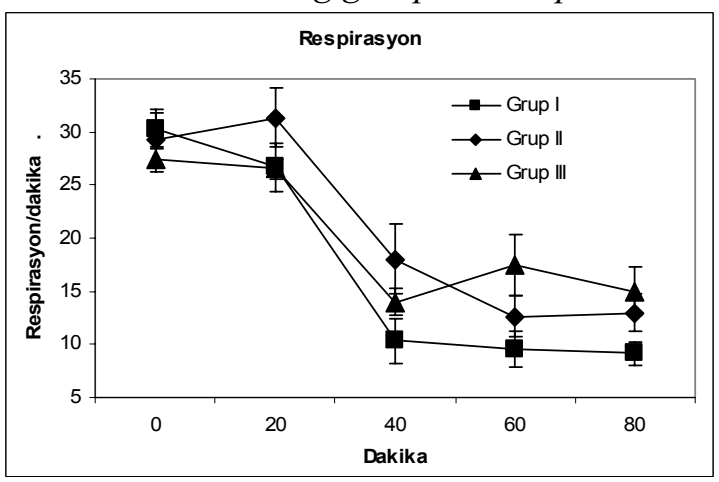

Şekil 3.

Deneme ve kontrol grubu köpeklerde ortalama respirasyon ve standart sapmalart.

*: $p<0,05, * *: p<0,01, * * *: p<0,001$.

Figure 3.

Mean of respiration and its standard deviation in control and working groups.

*: $p<0,05, * *: p<0,01, * * *: p<0,001$.

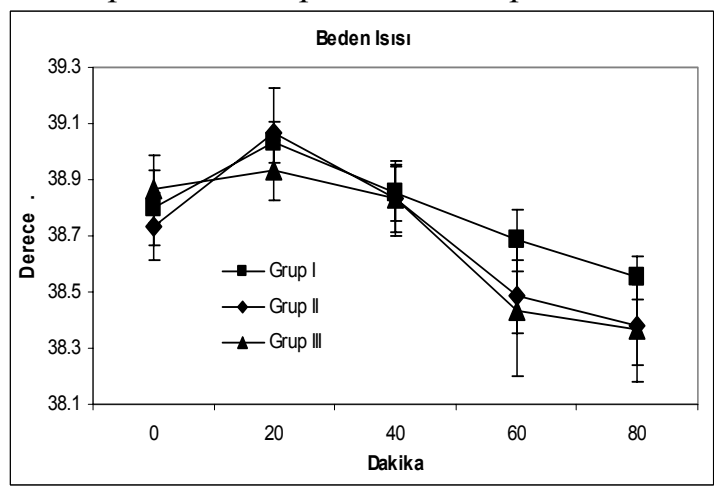

Şekil 4.

Deneme ve kontrol grubu köpeklerde ortalama beden islsl ve standart sapmalarl ***: $p<0,001$. Figure 4.

Mean of pulsation and its standard deviation in control and working groups. ${ }^{* * *}: p<0,001$.

\section{Tartışma ve Sonuç}

Üretral kateterizasyon, retrograde uretrosistografi, idrar kesesine lavaj uygulamalar1, ultrasonografi, radyografi, tıraş v.s. gibi işlemler sirasinda genellikle maniplasyona izin vermemelerinden dolayı köpeklerde yaygın olarak xylazine ile sedasyon uygulanmaktadır. Köpeklerde xylazine uygulamasının kusma, hipopnea, bradikardi, kardiyak kontraktilitede azalma, kardiyak output ve arteriyel kan basincında düşme gibi çeşitli komplikasyonları da bulunmakta$\mathrm{d}_{10}{ }^{16,18}$.

Perioperatif kusma ile histamin ve serotonin seviyelerindeki artış arasında bir ilişkinin olduğu, preanestezik ve anestezik uygulamalarından sonra vücutta histamin ve seratonin seviyelerinin arttığ bilinmektedir $^{11,19}$. Histamine bağ11 olarak oluşan perioperatif bulantı ve kusmanın önlenmesinde histaminerjik ve serotonerjik (5$\mathrm{HT}_{3}$ ) reseptör antagonistlerinin etkinliği bir süredir araştırılmaktadır ${ }^{2,5,13,20}$. Xylazine uygulamasına bağlı vücutta açığa çıkan histamin ve serotonin seviyeleri henüz bildirilmemiştir. $\mathrm{Bu}$ çalışmada xylazine uygulamasından sonra üçüncü gruptan sekiz köpeğin kusmas1, birinci ve ikinci gruptan birer köpeğin kusması, 1-2 mg/kg mepyramine uygulamasının xylazine bağlı kusmanın önlenmesinde her iki grupta \% 87,5 oranında, bulantının önlenmesinde birinci grupta \% 66,6 ve ikinci grupta \% 77,7 oranında etkili olduğunu göstermektedir. Araştırıcıların bildirdiği gibi xylazine bağlı bulantı ve kusmanın önlenmesinde mepyramine'nin area postremadaki $\mathrm{H}_{1}$ reseptörleri bloke ederek KTZ'un aktivasyonu ve dolayısıyla medullar kusma merkezinin uyarılmasını önlediği fikrini vermektedir. Nitekim, Bhargava ve ark. (1976) köpeklerde intracerebroventriküler histamin enjeksiyonu ile kusma oluştuğunu, histamin enjeksiyonundan önce intracerebroventriküler olarak uygulanan $\mathrm{H}_{1}$ reseptör antagonisti (mepyramine) enjeksiyonu ile önlenebileceğini göstermişlerdir. Gupta ve ark. (1989) köpeklerde intracerebroventriküler morfin enjeksiyonuna bağlı KTZ aktivasyonuyla kusma oluştuğunu, intracerebroventriküler naloxone (opioid antagonisti), mepyramine ve metiamide'nin enjeksiyonu ile morfine bağlı oluşan kusmanın önlendiğini bildirilmişlerdir. $\mathrm{Bu}$ çalışmada da uygulanan $\mathrm{H}_{1}$ reseptör antagonisti mepyramine'nin de beyin ve vücudun diğer bölümlerinde bulunan $\mathrm{H}_{1}$ reseptörlerini bloke ederek xylazine bağlı kusma oluşumunu önlediği düşünülmektedir. 
Hikasa ve ark. (1986) bir $\alpha_{2}$ adrenerjik reseptör agonisti olan xylazine'in $2 \mathrm{mg} / \mathrm{kg}$ dozda uygulandığında köpeklerde \% 81 oranında kusmaya neden olduğunu ve $\alpha_{2}$ adrenerjik reseptör antagonisti olan ilaçların (yohimbine, talozoline, phentolamine) xylazine'e bağlı kusmanın önlenmesinde etkinliklerini bildirmişlerdir. Bu ilaçlardan en etkilisi yohimbine olmasına karşın xylazine'in etkinliğini de ortadan kaldırdığ 1 için kusma kesici olarak kullanımının bir anlamı bulunmamaktadır. Xylazine uygulamasından sonra nervus vagusun ton'unda meydana gelen artışın KTZ'u aktive ettiği, bu aktivasyonun efferent impulslarla medullar kusma merkezini uyararak bulant1 ve kusma oluşturduğu da ileri sürülmektedir $^{3,21}$. Zabara (1988) yaptığ1 çalışmada nervus vagusu inhibe ederek xylazine'e bağl1 kusmay $\%$ 85 oranında önleyebilmiştir. $\mathrm{Bu}$ çalışmada, antihistaminik uygulanan gruplarda da birer köpeğin kusması ve iki köpekte bulantı semptomunun olması xylazine'e bağlı olarak oluşan kusmanın mekanizmasında $\mathrm{H}_{1}$ reseptörleri ve beyin histamininin yanı sıra $\mathrm{H}_{2}$ reseptörlerinin de uyarıldığııı, $\mathrm{H}_{2}$ reseptörlerinin uyarımıyla midedeki enterokromafin hücrelerden salınan histaminin mide pariyetal hücrelerini uyararak mide asit salgısını artırdığını, asit salgısındaki artışın nervus vagus'u uyararak afferent yolla KTZ'u aktive edebileceğini düşündürdü. $\mathrm{Bu}$ çalışmada bütün gruplardaki köpeklerde belirlenen bradikardinin nedeni de nervus vagus'un kolinerjik etkisinin artmasına bağlanabilir. Çalışmada kullanılan mepyramine'nin $\mathrm{H}_{1}$ reseptör antagonisti, midede bulunan reseptörlerin $\mathrm{H}_{2}$ reseptörler olması nedeni ile midede açığa çıkan histaminin etkileri ortadan kalkmamıştır. Bu çalı̧̧mada bütün gruplarda xylazine uygulamasının 20. dakikasında pulzasyonda önemli düşmelerin olması bir $\mathrm{H}_{1}$ reseptör antagonisti olan mepyramine'nin nervus vagus üzerinde inhibitör etkisinin olmadığını göstermektedir. İnsanlarda perioperatif bulantı ve kusmanın önlenmesinde $\mathrm{H}_{1}$ ve $\mathrm{H}_{2}$ reseptör antaganistlerinin birlikte kullanımının önemli derecede etkili olduğu iddia edilmektedir5.

Bu çalışmada antihistaminik uygulamasından 20 dakika sonra bütün köpeklerin klinik olarak normal görünümde ve sakin olmaları mepyramine'nin MSS üzerinde sakinleştirici etkisine bağlanabilir. Xylazine'in uygulama dozuna bağlı olarak respirasyon ve pulzasyonda oluştuğu ileri sürülen azalma ${ }^{12}$, bu çalışmada da bütün gruplarda xylazine uygulamasından 20 dakika sonra (çalışmanın 40. dakikasında) belirlendi $(\mathrm{p}<0,001)$. Antihistaminik uygulananlarda da bu azalışın saptanması, mepyramine uygulamasının xylazine bağlı bradikardi ve hipopnea'nın önlenmesinde etkili olmadığını göstermektedir. Köpeklerde xylazine uygulamasına bağlı olarak beden 1sısında istatistik önemi olmayan düşmelerin olacağ1 ileri sürülmektedir ${ }^{10}$. Bu çalışmada da xylazine uygulamasından 60 dakika sonra rektal beden 1sinda belirlenen hafif düşüşün istatistik önemi yoktu.

Xylazine uygulamasına bağlı oluşan bulant1 ve kusmanın bir $\mathrm{H}_{1}$ reseptör antagonisti olan mepyramine ile büyük oranda önlenmesi, xylazine bağli kusmada area postremada bulunan KTZ'un $\mathrm{H}_{1}$ reseptörleri tarafından aktive edildiği, bulantı ve kusmanın tam olarak önlenememesinde midedeki $\mathrm{H}_{2}$ reseptörlerinin bloke edilememesine bağlı olarak uyarılan nervus vagus'un afferent stimulasyonda etkisinin olabileceğini düşündürdü. Sonuç olarak, köpeklerde $1-2 \mathrm{mg} / \mathrm{kg}$ dozda mepyramine'in $2,2 \mathrm{mg} / \mathrm{kg}$ dozda xylazine'e bağl1 oluşan bulantı ve kusmanın önlenmesinde etkili olduğu, diğer klinik parametrelerde istatistik önemi bulunan bir değişikliğin olmadığı belirlendi.

\section{Kaynaklar}

1. BHARGAVA KP, DIXIT KS, PALIT G. Nature of histamine receptors in the emetic chemoreceptor trigger zone. Br. J. Pharmacol. 1976; 57: 211213.

2. CHOLWILL JM, WRIGHT W, HOBBS GJ,CURRAN J, Comparison of ondansetron and cyclizine for prevention of nausea and vomiting after day-case gynaecological laparoscopy. Br. J. Anaesth. 1999; 83: 611-614.

3. COLBY ED, McCARTHY LE, BORISON HL. Emetic action on the chemoreceptor trigger zone for vomiting in cats. J. Pharmacol. Ther. 1981; 4: 93-96.

4. CULLEN, M.C. Xylazine and medetomidine in small animals: these drugs should be used carefully. Aust. Vet. J., 1999; 77: 722-723.

5. DOENICKE AW, HOERNECKE R, CELIK I. Premedication with $\mathrm{H}_{1}$ and $\mathrm{H}_{2}$ blocking agents reduces the incidence of postoperative nausea and vomiting. Inflamm. Res. 2004; 53: 154-158.

6. FRIEDMAN LS, ISSELBACHER KJ. Nausea, vomiting, and indigestion. In: FAUCI AS, BRAUNWALD E, eds. Harrison's Principles of Internal Medicine. 14th ed. McGraw-Hill Companies, Inc. 1998. 
7. GUPTA YK, BHANDARI P, CHUGH A, SETH SE, DIXIT KS, BHARGAVA KP. Role of endogenous opioids and histamine in morphine induced emesis. Indian J Exp Biol. 1989; 27: 5254.

8. HIKASA Y, TAKASE K, OGASAWARA S. Evidence of the involvement of alpha 2adrenoceptors in the emetic action of xylazine in cats. Am. J. Vet. Res. 1989; 50: 1348-1351.

9. HIKASA Y, TAKASE $\mathrm{K}$, SAITO $\mathrm{K}$, OGASAWARA S. Antagonism of the emetic action of xylazine by alpha-adrenoceptor blocking agents. Eur. J. Pharmacol. 1986; 130: 229-235.

10. ILBÄCK NG, STALHANDSKE T. Cardiovascular effects of xylazine recorded with telemetry in the dog. J. Vet. Med. A., 2003; 50: 479-483.

11. KIMURA I, RUSCH D, STRASSER C, LENGKONG M, WULF H, CELIK I. Influence histamine release on postoperative vomiting following gynaecological laparoscopic surgery. Inflamm. Res. 2004; 53: 148-155.

12. KLIDE AM, CALDERWOOD HW, SOMA R. Cardiopulmonary effects of xylazine in dogs. Am. J. Vet. Res., 1975; 36: 931-935.

13. KRANKE P, MORIN AM, ROCWER N, EBERHART L. Dimenhydrinate for prophylaxis of postoperative nausea and vomiting: a metaanalaysis of randomized controlled trials. Acta Anaesthesiol. Scand. 2002; 46; 238-244.

14. KURTDEDE A, BÖRKÜ MK, GÜRKAN M. Xylazine hydrochloride (Rompun) ve Ketamine hydrochloride (Ketalar) uygulanan koyunlarda bazı klinik gözlemler. L.H.A.E.D., 1988; 28: 4250

15. LORENZ W, DUDA D, DICK W, SITTER H, DOENICKE A, BLACK A. Incidence and clinical importance of perioperative histamine release: randomized study of volume loading and antihistamines after induction of anaesthesia. Lancet 1994: 343; 933-940.

16. PADDLEFORD RR, HARVEY RC. Alpha2 agonists and antagonists. Vet. Clin. North. Am., 1999; 29: 737-745.

17. PİRINÇCI İ. Histamin ve antihistaminikler. In: KAYA S, PİRINÇCİ İ, BİLGiLI A, eds Veteriner Hekimliğinde Farmakoloji. Ankara: Medisan 557-571, 1997

18. RAND JS, REYNOLDS WT, PRIEST J. Echocardiographic evaluation of the effects of medetomidine and xylazine in dogs. Aust. Vet. J., 1996; 73:41-44.

19. RUSCH D, STASSER C, CELIK I, LENGKONG M, WULF II, SCHOLZ J. Vomiting after gynaecological laparoscopy under general anaesthesia is associated with changes of excretion of serotonin metabolites. Anaesthetist 2004: 53 ; 128-154.

20. UNSELD H, KAHNY B. Prophylaxe von postoperativem enhrechen durch HistaminRezeptorantagonisten. Anasth. Intensivmed. 1996; 1: 29-34.

21. ZABARA J. Neuroinhibition of xylazine induced emesis. Pharmacol. Toxicol. 1988; 63: 70-74. 